Síntesis: Este documento pretende reflexionar sobre los procesos de comunicación y de información en el contexto - previo, durante y posterior- del surgimiento y la estructuración de los Estado-nación latinoamericanos que cumplen 200 años. Expone diferentes interpretaciones acerca de cómo la comunicación y la información fueron articuladas en los proyectos de emancipación política e irradiación del ideario de "nacionalidad" en América Latina.

Palabras clave: comunicación, emancipación, periodismo, ciudadanía

Synthesis: This document aims to reflect on the processes of communication and information in the context-before during and post-emergence and structure of the Latin American nation-state 200 years a go. Suggests different interpretations of how communication and information were articulated in the project of political emancipation and irradiation of the ideology of "nationality" in Latin America.

Key Words: communication, empowerment, journalism, public

\section{¿200 años de qué? Comunicación, emancipación y exclusiones en América Latina}

Karina Herrera Miller Licenciada en ciencias de la comunicación, magíster en comunicación y desarrollo. Directora del Centro Interdisciplinario

Boliviano de Estudios de la Comunicación e-mail: khmiller21@gmail.com Fecha de recepción: 13-06-2010 Fecha de aprobación: 25-07-2010

Entre 2009 y 2010 una parte significativa de los más de treinta países de América Latina está conmemorando el llamado Bicentenario de su independencia, aquella transformación sustancial de su estatus de colonias europeas a Estado-nación soberanos. Resuenan los nombres de los llamados "Libertadores" o "padres de la patria"l, ensalzados por las gloriosas batallas libradas en suelo americano en busca de la emancipación. 
Dieron su vida, es cierto, al igual que setenta millones de habitantes originarios de esta tierras, en pos de su libertad.

El violento y temprano descontento contra la explotación y los abusos de los conquistadores fue protagonizado básicamente por las poblaciones nativas. Muchas de ellas incluso hicieron retroceder a las fuerzas españolas logrando que éstas desistieran de su afán expansionista ${ }^{2}$. Sin embargo, el proceso que culmina en la declaración de 15 nuevas Repúblicas en América Latina $^{3}$, empezó sistemáticamente desde el siglo XVIII. A finales de esa centuria, sobrevinieron alzamientos sangrientos de indígenas en busca de la reconquista de su territorio y cansados por los excesos inhumanos en el trabajo de mita, obrajes y minas; a principios del siglo XIX el movimiento insurreccional se extendió y desde México hasta Argentina y Chile comenzó casi al unísono una serie de rebeliones criollas e indígenas en contra del dominio colonial.

\footnotetext{
${ }^{1}$ Simón Bolívar, Antonio José de Sucre, Francisco de Miranda, Manuel Belgrano, Francisco de Paula Santander, Antonio Nariño, José de San Martín, José Artigas, Bernardo O'Higgins, Miguel Hidalgo y Costilla, Camilo Torres, Rafael Urdaneta, entre varios.

2 Por ejemplo, los indígenas araucanos de la región del Bío-Bío en Chile durante el siglo XVI; los indígenas de Cuba dirigidos por Atuey en 1511; las tribus de Jalisco en 1541, entre otras (CEDEP-CEDIS (Centro de Estudios y difusión social): Historia de las luchas populares. De la Conquista a la Independencia. Fascículo 1. Quito. 1990. Ver también sobre la lucha de los indígenas del Caribe a WHEELOCK ROMÁN, Jaime. Raíces indígenas de la lucha anticolonialista en Nicaragua. 7ma. edic. México: Siglo XXI. 1986.

${ }^{3}$ Estas corresponden a las actuales naciones de: Argentina, Bolivia, Colombia, Costa Rica, Chile, Ecuador, El Salvador, Guatemala, Honduras, México, Nicaragua, Paraguay, Perú, Uruguay y Venezuela. Mucho más tarde, se incorporarían al proceso independentista, pero de un modo distinto, República Dominicana (1844) y Cuba (1898). Ésta última logró ser nación soberana a través de la mediatización del intervencionismo norteamericano.
}

Esto es en breve lo que se evoca - no festeja, a decir de muchas voces que han optado por no entender este momento como una celebración-: la expulsión de tierras indoamericanas de la explotación administrada y el sojuzgamiento político-cultural de la península ibérica.

Bajo este marco, se pretende reflexionar sobre los procesos de comunicación y de información en el contexto - previo, durante y posterior- del surgimiento y la estructuración de los Estado-nación latinoamericanos que cumplen 200 años. Se busca ensayar interpretaciones acerca de cómo la comunicación y la información fueron articuladas en los proyectos de emancipación política e irradiación del ideario de "nacionalidad" en América Latina.

\section{Incomunicación colonial}

Como parte de este itinerario de pensamientos, será necesario fijar alguna noción de emancipación y entender para quiénes fue lograda la misma y, por supuesto, para quiénes no. Comprender además el tipo de emancipación que se dio y sus propios límites en un contexto marcado por un fuerte viraje en las relaciones mundiales.

Emancipación es un acto de libertad; libertad que sugiere una potestad de decisión autónoma sobre los actos presentes y futuros. Implica la natural autoridad de expresarse en términos propios sobre el acontecer de las cosas. Emancipar es un acto de autodeterminación, de supresión de las prerrogativas de una autoridad externa que norma sobre proceso ajeno.

Fue en este sentido que se logró la emancipación de carácter político -no plenamente social, cultural y económica- entre los dos primeros decenios del 


\section{Invitados}

siglo XIX en América Latina. Complejas y superpuestas fueron las causas para la abolición del coloniaje. Pueden mencionarse algunas de las más importantes:

- La crisis del imperio español y de su "rentismo", que lo llevó a ser un país improductivo, simple transmisor de los recursos extraídos de sus colonias hacia los centros metropolitanos del capitalismo financiero mercantil. España se vio atrapada así en una estructura señorial de poder, bajo la autoridad de una monarquía y de una iglesia represivas y corruptas 4 .

- La emergencia y consolidación del capitalismo mundial, que tuvo con el llamado "descubrimiento" de América un impulso notable en la ampliación del comercio intercontinental y la acumulación de capital sobre la base de las riquezas extraídas de los territorios colonizados y que precisó para el siglo XIX de la expansión de los mercados y el comercio libres.

- La difusión del Enciclopedismo y las repercusiones mundiales de la Revolución Francesay la Independencia norteamericana que dejaron huella en cierta llustración criolla latinoamericana, que no quiso soportar más los abusos hispánicos, expresados con notoriedad en las Reformas Borbónicas que impedían, por ejemplo, que

${ }^{4}$ QUIJANO, Aníbal. "Colonialidad del poder, eurocentrismo y América Latina". En: La colonialidad del saber: eurocentrismo y ciencias sociales. Perspectivas Latinoamericanas. Edgardo Lander (comp.) Buenos Aires: CLACSO, Consejo Latinoamericano de Ciencias Sociales. 2000. págs. 16 y 17. Disponible en: http://bibliotecavirtual.clacso.org. ar/ar/libros/lander/quijano.rtf

descendientes españoles nacidos en tierras colonizadas ocuparan cargos públicos jerárquicos.

- La imposibilidad ibérica de mantener el ritmo de expropiación de los recursos naturales, especialmente metales preciosos, habida cuenta del notable diezmo de la población indígena por causa de las inhumanas condiciones de trabajo esclavo, de las enfermedades y de las guerras insurreccionales ${ }^{5}$.

- La creciente ola de alzamientos de indígenas, mestizos y criollos que obligó a generar más controles político-militares, tener menos fuerza de trabajo

\footnotetext{
${ }^{5}$ Según narra Bartolomé de las Casas, religioso español defensor de los derechos de los indígenas esclavos, entre los años 1500 y 1540, la población nativa descendió de 15 a 12 millones por hambre, enfermedades, pero principalmente por el duro trabajo en las minas. En:CEDEP-CEDIS, Op. Cit. pág. 5.
} 
disponible, elevar los impuestos y ocasionar mayor descontento entre la población colonizada.

- La ocupación napoleónica de España en 1808 que dejó a la Corona ibérica debilitada para enfrentar la revuelta en los virreinatos americanos.

Este conjunto de episodios dio paso a los movimientos libertarios latinoamericanos.

La América colonizada por españoles y portugueses, principalmente, fue un escenario marcado tanto por graves problemas lingüísticos, como por otros derivados de una incomprensión estructural, resultado de las disímiles percepciones del mundo y de la vida entre peninsulares e indígenas y que acabó impidiendo una efectiva comunicación entre los distintos grupos.

No sólo el diverso origen de los colonizadores, sino además la estratificación sociorracial que inmediatamente se impuso, a decir del sociólogo Anibal Quijano ${ }^{6}$ como "codificación de las diferencias entre conquistadores y conquistados [fundada en] una supuesta diferente estructura biológica que ubicaba a los unos en situación natural de inferioridad respecto de los otros", alimentó un profundo estado de incomunicación, de deformación y de estereotipo de la imagen del "otro" entre sus habitantes.

Franklin Peace, historiador peruano, resume esta situación así: "se ha hecho notar que la actitud del

${ }^{6}$ QUIJANO, Aníbal. "Colonialidad del poder, eurocentrismo y América Latina", En: La colonialidad del saber: eurocentrismo y ciencias sociales. Perspectivas Latinoamericanas. Edgardo Lander (comp.) Buenos Aires: CLACSO, Consejo Latinoamericano de Ciencias Sociales. 2000. Disponible en: http://bibliotecavirtual.clacso.org.ar/ar/libros/ lander/quijano.rtf europeo en general no fue abierta al percibir y ver al americano, sino que en realidad buscó reconocer en los hombres y las sociedades americanas aquello que su propia historia europea le permitía aceptar"7.

El eje civilización-barbarie pasó a constituirse en el binomio explicativo de todo lo que empezó a narrarse, a normarse, de todo aquello que resultaba exótico, extraño e incomprensible, desde la sola óptica del extranjero.

En lo lingüístico, el apremio de someter al 96\% de la población que era indígena, orientó procesos tempranos de alfabetización, de comprensión, de estas lenguas nativas por parte española y de su posterior hispanización por medio del adoctrinamiento religioso. Si bien, como relata el investigador español sobre América precolombina, Georges Baudot, en el siglo XVI existieron al menos ciento cincuenta familias y grupos lingüísticos, que acogían entre cuatrocientas a dos mil lenguas según clasificaciones modernas; de ellas se acudió solamente a las lenguas hegemónicas tanto en la región mesoamericana como en las regiones de Nueva Granada y Perú: el náhuatl y el quechua y aymara, respectivamente ${ }^{8}$. Tanto el náhuatl como el quechua sirvieron para una cierta aproximación a los pueblos aborígenes. Sin embargo, la indagación sistemática tuvo la inmediata finalidad de emprender con eficacia tanto la evangelización de los indios como la explotación de su fuerza de trabajo?.

${ }^{7}$ PEACE, Franklin. "La Conquista española y la percepción andina del otro". En: Revista Histórica, Vol. XIII. No. 2. Diciembre. 1989, pág. 171.

${ }^{8}$ BAUDOT, Georges. La vida cotidiana en la América española en tiempos de Felipe II. Siglo XVI. 2da. Reimp. México: Fondo de Cultura Económica.1992, págs, 116-117.

${ }^{9}$ Con fortuna, más tarde, también sirvió para la recuperación de la memoria y el rescate cultural de los pueblos indoamericanos prehispánicos a través de cronistas indígenas o mestizos. 
Se enseñó a los nativos el español y el latín, gracias a la misión humanista de sacerdotes franciscanos, agustinos, dominicos, jesuitas, entre muchos. Algunos indígenas, especialmente los descendientes de la nobleza, fueron alfabetizados integralmente; se les enseñó a leer, escribir, contar e incluso a tocar instrumentos musicales para ser convertidos en este proceso en correas de inculcación religiosa hispánica entre su pueblo. De todas formas, la mayor parte de la población fue analfabeta, iletrada, aunque obviamente podía entender el español hablado ${ }^{10}$.

Esta breve semblanza del acontecer lingüístico en las colonias iberoamericanas es sólo una muestra de las dificultades para emprender procesos de entendimiento; el conocimiento de las lenguas nativas y su posterior hispanización se orientaron casi de un modo exclusivo al sometimiento religioso o laboral.

\section{La comunicación como cohesionadora del ideario emancipador}

Poco antes de iniciarse los procesos de independencia, en América Latina existía un reducido sector privilegiado que había accedido a la educación. Este grupo estaba conformado obviamente por los ciudadanos españoles asentados en América para los negocios o las funciones públicas, por el segmento criollo, por algunos mestizos, y excepcionalmente por los descendientes nobles indígenas que fueron instruidos para leer y escribir.

\footnotetext{
${ }^{10}$ Baudot explica la indefinición de la política española para extender la enseñanza del idioma en las colonias y erradicar de forma total las lenguas nativas. Se esperaba una hispanización lenta, a largo plazo, que llevó a tolerar la convivencia con otros idiomas, aunque se dejó en claro que ninguna de las lenguas aborígenes, inclusive el quechua, podía servir para los fines de la evangelización. Op, cit., págs. 123-124.
}

La inspiración libertaria tomó forma gracias a este grupo de letrados. Las discusiones de la incipiente burguesía criolla, ligada al comercio y molesta por las trabas señoriales españolas, fueron fundamentales en la construcción del ideario de liberación. Embebidos por el Enciclopedismo y el origen eufórico de la modernidad, donde la razón y el discurso científico empiezan a tener un sitial preferencial para la explicación del mundo natural y social, los criollos americanos buscaron completar su poderío económico con el político. Otra fuente relevante para los impulsos emancipadores fue el apoyo que desde Europa se recibió de los imperios inglés y francés, interesados en el libre tránsito de las mercancías entre los dos continentes, sin intermediación española.

Mariano Picón-Salas asegura que este ambiente fue el que propició e inspiró "la prosa clara y didáctica de los primeros 'Semanarios' y 'Gacetas'"1 1, amparada además en los mandatos de Carlos III, a finales del siglo XVIII, para erradicar la filosofía y la educación escolásticas.

En efecto, en el escenario previo a los levantamientos insurreccionales de principios del siglo XIX, Ia comunicación y la información sirvieron por sobre todo para propiciar la articulación ideológica de las élites criollas. Mediante debates, tertulias y encuentros, producidos en sociedades secretas, se empezó a definir las propuestas abolicionistas, a distribuir publicaciones manuscritas precarias sobre tales ideas y a intercambiar algunos libros censurados por la Corona española.

Se formó así un ideario independentista, emulando las entonces recientes experiencias francesa y

${ }^{11}$ PICÓN-SALAS, Mariano. De la Conquista a la Independencia. 3ra. Edic. México: Fondo de Cultura Económica.1994, pág. 199. 
norteamericana. Este proyecto pudo tomar forma definida por los procesos de producción, intercambio, circulación y recepción del sentido de Libertad, que fue inmediatamente favorable al sector comercial criollo y a los intereses también comerciales y expansionistas de Inglaterra y Francia.

Por otro lado, el proyecto indigenista de libertad se vio truncado tras los cruentos sofocamientos de las rebeliones de Tupac Amaru (Perú, 1780) y Tupac Catari (actual Bolivia: 1780-1781). La posición indígena se mostró vacilante ayudando a la vez a realistas y patriotas, además de dividirse en quienes creían en un proyecto de autodeterminación independiente, sin alianzas con mestizos y criollos y quienes, más bien, apoyaban en secundar a éstos ${ }^{12}$.

Bajo este panorama aparece el pasquín, libelo, corrido, o como diversamente se llamó a la comunicación manuscrita que fue más bien "intérprete de las pasiones y sentimientos de la época" antes que "divulgador de doctrinas", habida cuenta de dos factores que lo impedían: 1) la difícil distribución en amplias y dispersas zonas geográficas y 2) el analfabetismo extremo en las poblaciones coloniales ${ }^{13}$.

Aparecidos en América colonial a finales del siglo XVIII, los pasquines o libelos se convirtieron en un medio de protesta anónima y clandestina contra el abuso español ${ }^{14}$.

\footnotetext{
${ }^{12}$ MANRIQUE, Nelson. Historia de la República. Lima: Fondo Editorial de COFIDE.1995.

${ }^{13}$ MONTENEGRO, Carlos. Nacionalismo y coloniaje, 6ta. Edic. La Paz: Los Amigos del Libro.1982, pág. 28.

${ }^{14}$ Vitaliano Torrico afirma que diversos motivos, no sólo el político, se manifestaban en la utilización de los pasquines, por ejemplo el literario y el poético. TORRICO PANOZO, Vitaliano. El pasquín en la independencia del Alto Perú. México: Plaza y Valdes S.A.1997.
}

Está claro que los promotores de tales comunicaciones fueron criollos o mestizos letrados que trataban de azuzar el candente descontento por los desiguales privilegios.

Su carácter de manuscrito se debe fundamentalmente a que la imprenta, como tecnología principal de aquella época, estuvo resguardada por la iglesia y las autoridades españolas en tierras americanas. Existía un monopolio para su uso con fines evangelizadores, educativos o político-administrativos ${ }^{15}$, además de censura previa en contra de la publicación de varios libros, por lo que no es difícil entender el porqué aparecen las protestas manuscritos. Otro motivo fue el gusto por la escritura a mano, especialmente en el denominado Alto Perú, pues a través de aquella pasaba todo lo concerniente a la seguridad de intereses, como títulos de propiedad, nombramientos nobiliarios 0 político-administrativos ${ }^{16}$.

En esta etapa, las reuniones, las discusiones, la organización de las llamadas Sociedades de Amigos del País ${ }^{17}$, las logias y grupos secretos, los claustros universitarios, es decir, la comunicación reflexiva y conspirativa tuvo un papel indudablemente más relevante en la cohesión de las ideas emancipadoras que propiamente el periodismo que empezó a

\footnotetext{
${ }^{15}$ La imprenta llegó a México por primera vez en el año de 1540. La primera Relación que se conoce es la de 1541 con el título de "Relación del espantable terremoto que agora nuevamente ha acontecido en la ciudad de Guatemala: es cosas de grande admiración y de grande ejemplo para que todos nos enmendemos a nuestros pecados $y$ estemos apercibidos para cuando Dios fuere seguido de nos llamar". ${ }^{16}$ TORRICO PANOZO, Op. Cit., pág. 61.

17 De origen europeo, estas organizaciones se constituyeron con el fin de incentivar las distintas actividades económicas (agricultura, comercio, industria), bajo una inspiración liberal, tratando de expandir los planteamientos de la llustración. En América Hispana se conformaron de igual manera estas instituciones que chocaron contra la censura oficial de la Corona y las condiciones mismas del dominio ibérico.
} 


\section{Invitados}

gestarse ya sea como lo anota el investigador boliviano Gustavo Adolfo Otero en las Gacetas, Hojas volantes o Relaciones que se publicaron en América Latina a fines del siglo XVIII' ${ }^{18}$, en donde se disimula la crítica contra la Corona española o bien, como más tarde se hizo, con las subversivas publicaciones manuscritas y clandestinas que anteceden a los levantamientos en la región. De esta forma, "El periodismo escrito, complementado con la comunicación oral -el primero incipiente y la segunda tradicional - fue importante sustento de la lucha independentista. Combinando añejos modos con nuevas formas de información, los comunicadores de la época pusieron a valer sus capacidades y su imaginación, recogieron la ideología revolucionaria y divulgaron sus mensajes de manera oportuna, a pesar del elevado analfabetismo"19.

\section{Periodismo, nacionalidad y ciudadanía}

Tras los primeros movimientos libertarios ${ }^{20}$ que iniciaron los 15 años de la Guerra por la Independencia en América Latina, la comunicación, la información y la propaganda se subsumieron en las publicaciones realizadas desde las filas militares de los ejércitos patriotas o contrarrevolucionarios.

Como afirma Otero (1953: 111 ) "Durante las campañas de la independencia la prensa es una prolongación del Ejército, su papel está en cooperar a las milicias para mantener la moral en el pueblo, dando cuenta de los

${ }^{18}$ OTERO, Gustavo Adolfo. La cultura y el periodismo en América, 2da. Edic. Quito: Casa editora Liebman.1953, pág. 95.

${ }^{19}$ ASCARRUNZ, Eduardo. Ideología política y comunicación social en el proceso histórico de la Colonia a la Independencia. En: Revista Signo. Cuadernos bolivianos de cultura No.. 35. La Paz: Don Bosco. 1992, pág. 65.

${ }^{20}$ El de Sucre el 25 de mayo de 1809 y el de La Paz del 16 de julio de ese mismo año, en lo que hoy es Bolivia. triunfos y explicando las derrotas" ${ }^{\prime 21}$. El periodismo, como realización moderna de una comunicación pública, se convirtió para esta época en una estrategia de igual valor que la militar, destinada a organización, información, propaganda, contrapropaganda y movilización de los ejércitos y de su apoyo popular. Existen varios relatos de cómo los ejércitos se movilizaron cargando, además de todo el arsenal bélico, con equipos de imprenta, lo que brinda una cabal idea de su absoluta relevancia.

Ya en tierras que paulatinamente fueron liberadas, se instalaron periódicos o Gacetas oficiales bajo la tuición de los gobiernos patriotas ${ }^{22}$. En Argentina, "La Gazeta de Buenos Aires" (1810), cuyo primer director fue el prócer Mariano Moreno; en Bolivia se fundó "El Chuquisaqueño" (1825) y más tarde "El Cóndor de Bolivia", dirigido por el propio Mariscal Antonio José de Sucre; en Colombia, bajo los influjos de una gran confederación, apareció el periódico creado por el propio Simón Bolívar "El Correo del Orinoco" (1818) y luego "La Gaceta de Santa Fé de Bogotá"; en Venezuela se fundó "La Gaceta de Caracas" (1808), periódico cuestionado por su ambivalencia durante la guerra de la independencia del lado realista y patriota; en Uruguay "La Gaceta de Montevideo" (1810); en Perú se publicaron varios diarios inspirados en la estructuración republicana; en Paraguay el periódico "El Paraguay Independiente" (1845); en México "El Despertador Americano" (1810); en Ecuador "El Patriota de Guayas" (1812); en Chile "El Mercurio" y "El Araucano" (1812); en Costa Rica "Noticioso Universal de Costa Rica" (1833). Cuba durante la campaña libertadora de 1895 y 1989 edita varios impresos como "La Patria" y "El Yara", para citar algunos ejemplos.

\footnotetext{
${ }^{21}$ Otero. Op.cit. Pág 111
}

${ }^{22}$ Las referencias de nombres de diarios y fechas son tomadas de OTERO, Op. cit. 
Este conjunto constituye una prueba de cómo la prensa fue una de las instituciones que rápidamente se organizó —o fue organizada-, luego de logrados los triunfos independentistas, ante las necesidades de estructuración de las recientes repúblicas.

El periodismo entró a formar parte de los dispositivos de organización y de legitimación de los Estado-nación. Éstos pasaron, aunque simbólicamente, a representar la síntesis del "bien común", el espacio en donde convergían los intereses de todos, aunque en los hechos sólo se constituyeron alrededor de los intereses de la elite local que sustituyó al poder colonial.

Las nuevas sustancias geográficas, políticas y socioculturales precisaron asimismo de una "nueva subjetividad" que vino a ser formalizada a través del concepto de "ciudadano". Para esta construcción, según analiza Santiago CastroGómez ${ }^{23}$ tomando como base el estudio de la venezolana Beatriz González ${ }^{24}$, fueron necesarias ciertas prácticas disciplinarias que forjaran a los ciudadanos latinoamericanos del siglo XIX. AI respecto se identifican tres que fueron principales: 1) las Constituciones; 2) los manuales de urbanidad; y 3) las gramáticas de la lengua; y a las que se añadiría, para los fines de este trabajo, los periódicos que se crean en la etapa de organización republicana.

${ }^{23}$ CASTRO-GÓMEZ, Santiago. "Ciencias sociales, violencia epistémica y el problema de la "invención del otro". En: LANDER, Edgardo (comp.). La colonialidad del saber: eurocentrismo y ciencias sociales. Perspectivas Latinoamericanas. Buenos Aires: CLACSO, Consejo Latinoamericano de Ciencias Sociales.2000. Disponible en la World Wide Web: http:// bibliotecavirtual.clacso.org.ar/ar/libros/lander/castro.rtf

${ }^{24}$ GONZALEZ STEPHAN, Beatriz. "Economías fundacionales. Diseño del cuerpo ciudadano". En: Cultura y Tercer Mundo. Nuevas identidades y ciudadanías. Caracas: Nueva Sociedad.1996.
Todas estas prácticas y tecnologías, según González Stephan, citada por Castro-Gómez, descansaron en la legitimidad que les otorga la escritura. Así en este específico momento, "La palabra escrita construye leyes e identidades nacionales, diseña programas modernizadores, organiza la comprensión del mundo en términos de inclusiones y exclusiones. Por eso el proyecto fundacional de la nación se lleva a cabo mediante la implementación de instituciones legitimadas por la letra (escuelas, hospicios, talleres, cárceles) y de discursos hegemónicos (mapas, gramáticas, constituciones, manuales, tratados de higiene, [periódicos]) que reglamentan la conducta de los actores sociales, establecen fronteras entre unos y otros y les transmiten la certeza de existir adentro o afuera de los límites definidos por esa legalidad escrituraria"25.

Investigaciones llevadas adelante sobre "El Cóndor de Bolivia" $^{26}$, por ejemplo, periódico que se convirtió en el vocero oficial apenas Bolivia logró su independencia el 6 de agosto de 1825, concluyen que las principales funciones que cumplió este órgano de difusión fueron:

- Servir a los propósitos organizativos de la República y de su administración.

- Difundir ideas antirreligiosas y expresar el pensamiento de los libertadores.

- Construir el sentimiento nacional. - Instalar una idea de lo público.

${ }^{25}$ CASTRO-GÓMEZ, Santiago. Op. cit. pág. 3.

${ }^{26}$ PINTO, Esperanza. "Bolivia: el estado de la comunicación en el período organizativo de la República 1825-1828”. En: Memoria Académica I Encuentro Nacional y I Seminario Latinoamericano de Investigación de la Comunicación. 2000. La Paz:ABOIC (Asociación Boliviana de Investigadores de la Comunicación) - CIBEC (Centro Interdisciplinario Boliviano de Estudios de la Comunicación). Y RUCK URIBURU CRESPO, Andrea. El cóndor de Bolivia: la ideología republicana en el primer periódico de Bolivia (1825-1828). Tesis en Ciencias de la Comunicación de la Universidad Católica Boliviana La Paz. Documento inédito. 1997. 


\section{Invitados}

- Inseminar ideas, sentimientos, conductas y acciones en el marco del nuevo orden.

- Educar al pueblo sobre temas de soberanía, sistema de representación, llustración.

- Anular ideas discrepantes.

- Extender el espíritu republicano.

El modelo de ciudadano ${ }^{27}$, de subjetividad necesaria para el proyecto de la modernidad que se visualizó en y tras los procesos de Independencia, se filtró en los intersticios del discurso periodístico, que interpeló básicamente a la nueva elite conformada por hombres letrados y con cierta capacidad económica y dejó por fuera de la "ciudad letrada" a mujeres, analfabetos, indios, esclavos, sirvientes, etc. ${ }^{28}$.

\section{La exclusión comunicacional letrada}

Con este sistema de inclusión/exclusión instituido por la letra y el idioma en la etapa de nacimiento de Estados modernos en América Hispana, se prolongó y se ratificó, asimismo, aquella exclusión comunicacional ${ }^{29}$ que comenzó con la Conquista española y portuguesa desde 1492. Ésta, como se mencionó, tuvo su principal causa en la profunda incomprensión ibérica de las culturas nativas por la que "los pueblos conquistados y dominados fueron situados en una posición natural de inferioridad y, en consecuencia, también sus rasgos fenotípicos, así como sus descubrimientos mentales y culturales"30

${ }^{27}$ Según Castro, este modelo corresponde a un varón, blanco, católico, padre de familia, propietario, letrado y heterosexual.

28 Ibid.

${ }^{29}$ MARQUES DE MELO, José. "Exclusión comunicacional y democracia mediática: dilema brasileño en el umbral de la sociedad y la información", En: Telos. Cuadernos de Comunicación e Innovación No. 51, Segunda Época. Madrid: Fundación Telefónica. 2001, págs. 28-32.

${ }^{30}$ QUIJANO, Aníbal. Op. cit. pág. 2.

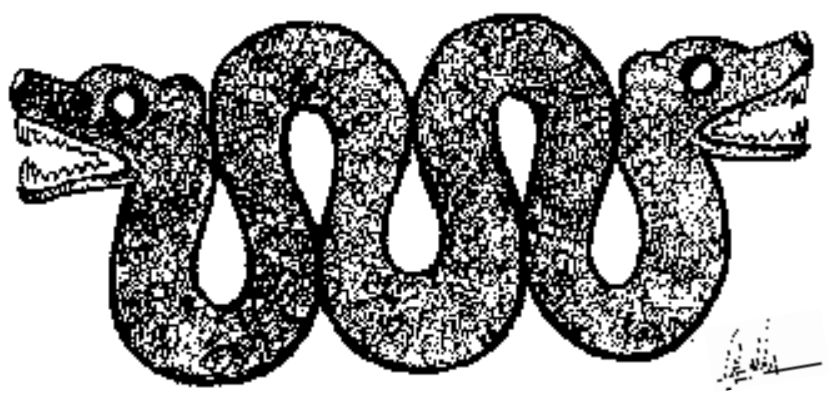

y con ellos, por supuesto, todos sus dispositivos, sistemas y formas de comunicación.

Las Repúblicas a través de sus Constituciones o Cartas Magnas, reconocieron, bajo el espíritu liberal de la época, la igualdad civil de todos los habitantes y la libertad de expresión y de prensa como requisitos indispensables para el funcionamiento de los nuevas naciones, aunque paradójicamente no lograron ni discutir ni compartir las bases de estos escritos con el grueso de la población ni tampoco garantizar el que pudieran ejercer tales derechos. Campesinos, indios, mujeres, negros, sirvientes, y sectores marginados desde la Colonia fueron sistemáticamente relegados de la intervención pública y de cualquier otra forma de participación en la toma de decisiones.

La prensa durante los procesos de constitución de los Estado-nación sirvió como plataforma de discusión pública y de recurrentes enfrentamientos corporativos de dirigentes, caudillos, próceres y demás elite política que dejó sin margen a la representación opinativa de excluido/as. Al respecto, el investigador brasileño José Marques de Melo afirma que: "A pesar de contar con unos medios impresos de comunicación gobernados por la doctrina de la libertad de expresión y pensamiento, las repúblicas hispano-americanas y el imperio luso- 
brasileño consolidaron modelos informativos erigidos como privilegio de las élites. Considerando que los grandes contingentes de las poblaciones nacionales estaban formados por trabajadores iletrados, libres o esclavos, viviendo en el campo o en las ciudades, la información impresa se convirtió históricamente en espacio disfrutado apenas por las clases superiores, incluyendo a las capas medias beneficiadas por los conocimientos adquiridos en la escuela" ${ }^{\prime 31}$.

La palabra escrita e impresa y los intentos de homogeneidad lingüística por medio de la literatura y del periodismo impusieron, sin un éxito total, una forma política de pensamiento único. Así, si bien se logró una emancipación política del domino ibérico, las sociedades latinoamericanas y en especial las del Sur siguieron reproduciendo los esquemas de la colonización, al someter y excluir política, social, cultural y comunicacionalmente a una importante base social.

\section{Apropiaciones des-letradas}

Por ello no parece extraño, que al estar al margen del sistema escolar formal, de la participación electoral y desde luego de la discusión pública de los intereses colectivos, elementos-base de la moderna ciudadanía, los sectores marginados con el trascurrir del tiempo hayan tenido que apropiarse de espacios y tecnologías que son antípodas de la palabra escrita. Así, al hacerse más evidente la crisis del discurso liberal excluyente en todo lo que va del siglo XIX y gran parte del siglo $X X$, los sectores populares tomaron por ejemplo a la radio como mecanismo expresivo y como instrumento

${ }^{31}$ MARQUES DE MELO, José. "Paradigmas comunicacionales que brotaron tempranamente en las Américas". En: Quórum Académico. Vol. 1, No. 1. Enero - Junio de 2004, pág. 26. estratégico de sus demandas sociales y políticas históricamente soslayadas.

La radio en América Latina, desde finales de 1940, empezó a ser empleada por sectores excluidos o por organizaciones sociales en asistencia a éstos. En Bolivia, en 1947 se dio paso a un modelo de comunicación autogestionario popular e interpelador de las estructuras de poder, a través de lo que fue la radiodifusión sindical minera. Esta pionera iniciativa de comunicación del pueblo y para el pueblo se extendió por toda la región hasta crecer y constituirse en la realidad comunicacional paralela $-\mathrm{y}$ contrahegemónica en

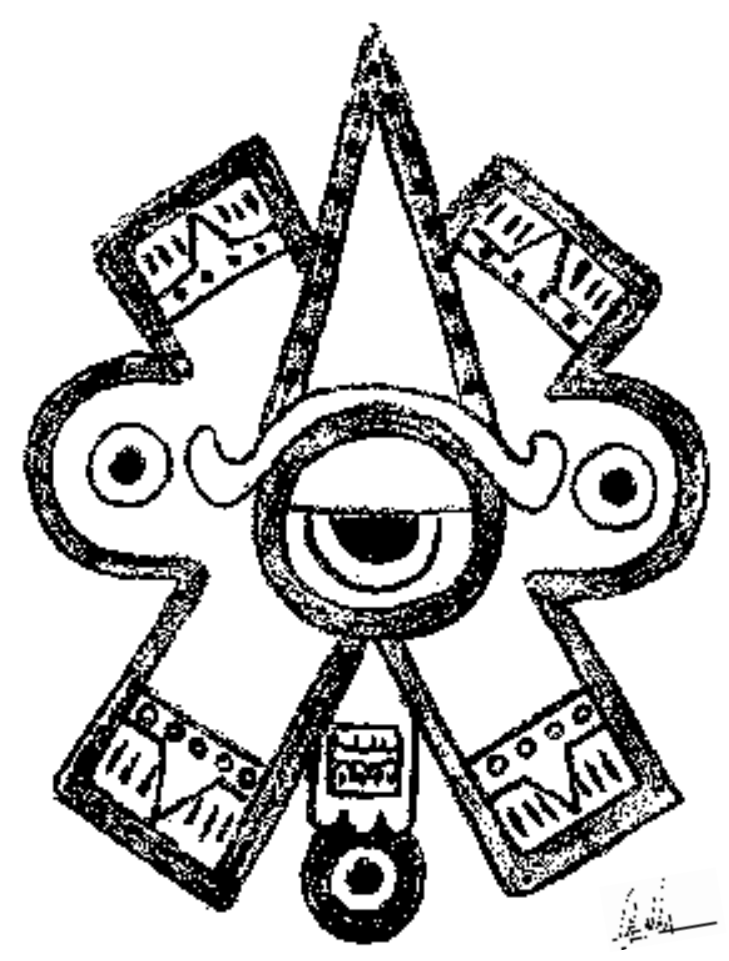




\section{Invitados}

una mayoría de casos- que es hoy día expresada en sus denominativos de comunitaria, popular, alternativa, indígena, campesina, etc.

Con el paso del tiempo, pese a que se avanzó relativamente en la alfabetización de las masas y en su acceso educativo, la población carente de la garantía de condiciones de vida digna, sigue apostando por la radio no sólo por representar un medio de más fácil acceso y bajo costo, sino y fundamentalmente porque está constituida desde la oralidad, desde lenguajes y narrativas que no le han sido ajenos ni negados como en el caso de lo escritural occidental.

Los esquemas de poder mundial que se instalaron en América Latina en el escenario de las posguerras mundiales, sustituyeron el discurso que oponía civilización-barbarie en la época colonial, por modernidadatraso o lo que duró hasta nuestros días a través del binomio desarrollosubdesarrollo.

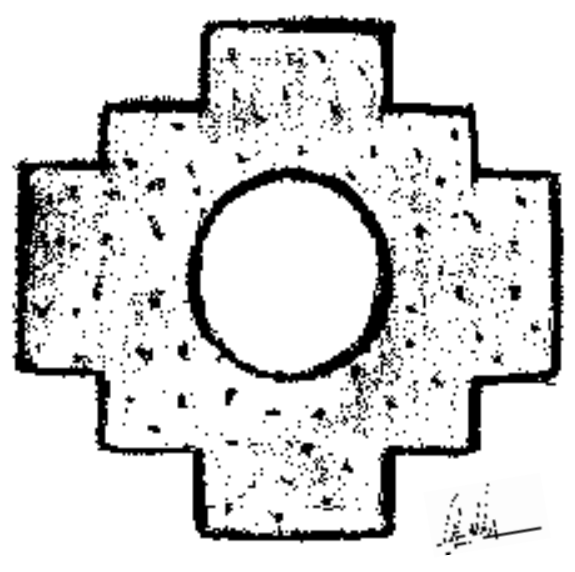
la expulsión del sistema colonial ibérico, sigue siendo, sin embargo, una realidad matizada por las viejas y nuevas inequidades $y$ exclusiones. "Desde México hasta la Patagonia, continúan en vigor panoramas caracterizados por la depresión cultural de las grandes masas que generalmente están distanciadas o fueron precozmente expulsadas de las redes educativas formales. Los mayores contingentes humanos de América Latina se nutren de conocimientos efímeros,

Al hablar de comunicación para el desarrollo, por ejemplo, no se puede menos que pensar en un itinerario largo, de más de seis décadas, en que no sólo los conceptos y las nociones sobre comunicación y desarrollo por separado han cambiado, sino también la misma relación entre ellos. Profundas críticas teóricas se instalaron en la década de 1960 desde América Latina sobre las simplificadas concepciones de comunicación, entendidas sólo como persuasión o transmisión informativa, y sobre desarrollo comprendido desde su origen modernizador evolucionista y occidental. fragmentados y superficiales solamente propiciados por las "escuelas paralelas" que brotan de las redes mediáticas. Así ha crecido la categoría de ciudadanos de segunda clase, más ineficaces o inapetentes, en el sentido de actuar democráticamente como sujetos de su propia Historia" ${ }^{\prime \prime 2}$. N

${ }^{32}$ MARQUES DE MELO, 2004, Op. cit. pág, 27. 


\section{Bibliografía}

ASCARRUNZ, Eduardo. Ideología política y comunicación social en el proceso histórico de la Colonia a la Independencia. En: Revista Signo. Cuadernos bolivianos de cultura No. . 35. La Paz: Don Bosco. 1992.

BAUDOT, Georges. La vida cotidiana en la América española en tiempos de Felipe II. Siglo XVI. 2da. Reimp. México: Fondo de Cultura Económica. 1992.

CASTRO-GÓMEZ, Santiago. "Ciencias sociales, violencia epistémica y el problema de la "invención del otro", En: LANDER, Edgardo (comp.). La colonialidad del saber: eurocentrismo y ciencias sociales. Perspectivas Latinoamericanas. Buenos Aires: CLACSO, Consejo Latinoamericano de Ciencias Sociales.2000. Disponible en: http://bibliotecavirtual.clacso.org.ar/ar/libros/lander/ castro.rtf

CEDEP (Centro de Educación Popular) - CEDIS (Centro de Estudios y difusión social) : Historia de las luchas populares. De la Conquista a la Independencia. Fascículo 1. Quito. 1990.

GARGUREVICH, Juan. Historia de la prensa peruana. 1594-1990. Lima: La Voz ediciones. 1991.

GONZALEZ STEPHAN, Beatriz. "Economías fundacionales. Diseño del cuerpo ciudadano", En: Cultura y Tercer Mundo. Nuevas identidades y ciudadanías. Caracas: Nueva Sociedad. 1996.

MANRIQUE, Nelson. Historia de la República. Lima: Fondo Editorial de COFIDE. 1995.

MARQUESDE MELO, José. "Paradigmas comunicacionales que brotaron tempranamente en las Américas". En:
Quórum Académico. Vol. 1, No. 1. Enero - Junio de 2004.

MARQUES DE MELO, José. "Exc/usión comunicacional y democracia mediática: dilema brasileño en el umbral de la sociedad y la información", En: Telos. Cuadernos de Comunicación e Innovación No. 51, Segunda Época. Madrid: Fundación Telefónica. 2001, págs. 28-32.

MONTENEGRO, Carlos. Nacionalismo y coloniaje, 6ta. Edic. La Paz: Los Amigos del Libro. 1982.

OTERO, Gustavo Adolfo. La cultura y el periodismo en América, 2da. Edic. Quito: Casa editora Liebman. 1953.

PEACE, Franklin. "La Conquista española y la percepción andina del otro". En: Revista Histórica, Vol. XIII. No. 2. Diciembre. 1989, págs. 171-196.

PICÓN-SALAS, Mariano. De la Conquista a la Independencia. 3ra. Edic. México: Fondo de Cultura Económica. 1994.

PINTO, Esperanza. "Bolivia: el estado de la comunicación en el período organizativo de la República 18251828", En: Memoria Académica I Encuentro Nacional y I Seminario Latinoamericano de Investigación de la Comunicación. 2000,La Paz: ABOIC (Asociación Boliviana de Investigadores de la Comunicación) - CIBEC (Centro Interdisciplinario Boliviano de Estudios de la Comunicación).

QUIJANO, Aníbal. "Colonialidad del poder, eurocentrismo y América Latina", En: La colonialidad del saber: eurocentrismo y ciencias sociales. Perspectivas Latinoamericanas. Edgardo Lander (comp.) Buenos Aires: CLACSO, Consejo Latinoamericano de Ciencias 
Sociales. 2000. Disponible en: http://bibliotecavirtual. clacso.org.ar/ar/libros/lander/quijano.rtf

RUCK URIBURU CRESPO, Andrea. El cóndor de Bolivia: la ideología republicana en el primer periódico de Bolivia (1825-1828). Tesis en Ciencias de la Comunicación de la Universidad Católica Boliviana La Paz. La Paz. Documento inédito. 1997.

TORRICO PANOZO, Vitaliano. El pasquín en la independencia del Alto Perú. México: Plaza y Valdes S.A. 1997

WHEELOCK ROMÁN, Jaime. Raíces indígenas de la lucha anticolonialista en Nicaragua. 7ma. edic. México: Siglo XXI. 1986. 